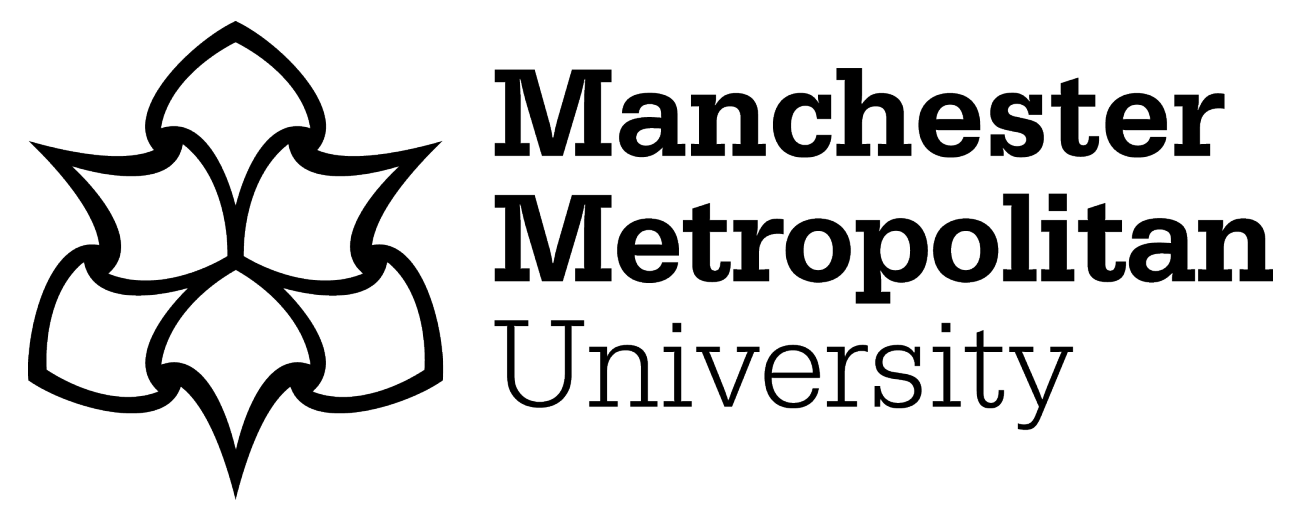

Allen, NS, Mahdjoub, N, Vishnyakov, V, Kelly, PJ and Kriek, RJ (2018) The effect of crystalline phase (anatase, brookite and rutile) and size on the photocatalytic activity of calcined polymorphic titanium dioxide (TiO2). Polymer Degradation and Stability, 150. pp. 31-36. ISSN 0141-3910

Downloaded from: https://e-space.mmu.ac.uk/620390/ Publisher: Elsevier

DOI: https://doi.org/10.1016/j.polymdegradstab.2018.02.008 Usage rights: Creative Commons: Attribution-Noncommercial-No Derivative Works 4.0

Please cite the published version 


\title{
The effect of crystalline phase (anatase, brookite and rutile) and size on the photocatalytic activity of calcined polymorphic titanium dioxide $\left(\mathrm{TiO}_{2}\right)$
}

\author{
Norman S. Allen ${ }^{\mathrm{a}}$, Noredine Mahdjoub*c, Vladimir Vishnyakov ${ }^{\mathrm{b}}$, Peter J. Kelly ${ }^{\mathrm{b}}$ and Roelof J. Kriek ${ }^{\mathrm{c}}$ \\ ${ }^{a}$ Chemistry and Environmental Sciences Department \\ ${ }^{\mathrm{b}}$ Surface Engineering Group \\ Faculty of Science and Engineering, The Manchester Metropolitan University \\ Chester Street, Manchester M1 5GD, UK \\ ${ }^{\mathrm{c}}$ Electrochemistry for Energy \& Environment Group, Research Focus Area: Chemical Resource \\ Beneficiation (CRB), North-West University, Private Bag X6001, Potchefstroom 2520, South Africa \\ *Corresponding Author; E-mail: Noredine.Mahdjoub@gmail.com, Tel.: +27 (0)18 2991668 \\ *Contact Authors; E-mail: Peter.kelly@mmu.ac.uk; Norman_allen@sky.com
}

\begin{abstract}
The effect of thermal treatment on the morphology (crystalline phase and size) and photocatalytic activity of freshly prepared $\mathrm{TiO}_{2}$ nano-powder is communicated. $\mathrm{TiO}_{2}$ nano-powders, prepared by hydrolyzing titanium tetraisopropoxide at room temperature, were all dried at $382 \mathrm{~K}$ and subsequently calcined at different temperatures, for one hour, up to $1172 \mathrm{~K}$. Raman analysis of each thermally treated sample exhibited different titania phase structures. Up to $772 \mathrm{~K}$ a mixture of brookite and anatase phases was observed, while a mixture of all three phases, i.e. anatase, brookite and rutile, was observed at 872 $\mathrm{K}$, with a rutile only phase at $1097 \mathrm{~K}$ and above. The photocatalytic activity of all samples was assessed by means of the photocatalytic degradation of methyl orange dye $(\mathrm{MeO})$. All anatase-brookite compositions exhibited high photocatalytic activity with the rate of degradation decreasing with increasing calcination temperature, which coincides with (i) a slight increase of the anatase phase, (ii) a slight decrease of the brookite phase, and (iii) a gradual increase of the crystallite size of all phases. The greatest photocatalytic activity was observed for the sample calcined at $382 \mathrm{~K}$, which contained the highest amount of brookite (in the presence of anatase as the dominant phase), while the lowest rate was observed for the pure rutile sample.
\end{abstract}

Keywords: $\quad$ titanium dioxide, anatase, brookite, rutile, photocatalytic, thermal treatment 


\section{Introduction}

Titanium dioxide is a polymorphic material (anatase, brookite and rutile) used in applications such as photocatalysis, filler for polymers and coatings, solar cells, deodorizing and as a luminescent material [1-5]. Except for its wide application in the pigment and ceramic industries, nanocrystalline titanium dioxide $\left(\mathrm{TiO}_{2}\right)$ has been attracting much interest as a result of its effectiveness in acting as a semiconducting photocatalyst to break down and remove pollutants from air or water $[5,6]$. The photocatalytic degradation of organic pollutants has in fact drawn so much attention that a number of review papers on this specific application of semiconductor titania has 'seen the light' [7-9]. This has been complemented by a number of review papers on the general process of semiconductor photocatalysis $[5,10,11]$.

Titania can be extracted from minerals or prepared from solutions of titanium salts or alkoxides through one of many known routes, which includes the sulphate process, the chloride process, the hydrothermal method or the sol-gel process [12-14]. Rutile is the stable form, whereas anatase and brookite are metastable and are readily transformed to rutile when heated [15]. In rutile, two opposing edges of an octahedron are shared to form linear chains along the edge direction, and the $\mathrm{TiO}_{6}$ chains are linked to each other via corner connections. Anatase has no edge sharing but has four corners shared per octahedron. The crystal structure of anatase, which is tetragonal, can be viewed as zigzag chains of the octahedra linked together through corner sharing. In brookite, on the other hand, the octahedrons share both edges and corners, forming an orthorhombic structure [16, 17]. Anatase is the phase normally found as a result of the sol-gel syntheses of $\mathrm{TiO}_{2}$, whereas brookite is often only observed as a byproduct. The hydrothermal synthesis of titania normally results in mixed anatase and brookite structures at lower temperatures with conversion to pure rutile at high temperatures [18-20], with some studies having been conducted on the kinetics of the transformation of brookite to rutile [21-23]. Although it is rather difficult to prepare, the synthesis of pure brookite (in the absence of anatase or rutile) has been achieved of late [24-28]. The number of instances that high purity single phase brookite has been synthesised is, however, extremely limited at present [29-31].

Of the three crystal structures anatase and rutile are the most common and to that regard the amount of research that has been conducted on anatase and rutile as photocatalysts by far outweighs the effort that has been afforded to brookite. It is commonly accepted that anatase is a more capable photocatalyst (compared to rutile and brookite), which is evident from the numerous studies that have highlighted the photocatalytic application of $\mathrm{TiO}_{2}$ (with specific reference to the anatase crystalline phase) [29, 32]. Rutile by itself has hardly ever been found to be active for the photodegradation of organic compounds in aqueous solutions, but satisfactory levels of photocatalytic activity have been exhibited by samples containing mixtures of anatase and rutile $[33,34]$. Brookite, as a semiconductor photocatalyst, has thus far received much less interest with regard to the role that it plays in the photocatalytic activity of 
titanium dioxide nano-powders, which is probably due to the difficulties experienced in producing pure brookite. A number of studies, however, do indicate that brookite nanocrystals have excellent photocatalytic capabilities for, amongst others, the dehydrogenation of 2-propanol [4, 27], the photocatalytic oxidation of methanol [35], and the degradation of Orange II dye [30].

The photocatalytic activity of calcined titania, prepared by hydrolyzing titanium tetraisopropoxide, has been probed earlier [15], albeit at different temperatures, and it was found that anatase-brookite compositions all exhibited photocatalytic activity, as determined by the photocatalytic degradation of methyl orange. This study, investigating the photocatalytic activity of heat-treated polymorphic titanium dioxide nano-powders (with the focus on brookite content), builds on our previous work [15] as the calcination temperature range is extended so as to provide a more encompassing and clear analytical picture.

\section{Experimental}

Titanium dioxide, in nano-powder form, were prepared by hydrolyzing titanium tetraisopropoxide at room temperature by adding the isopropoxide in a drop-wise manner to demineralized water. The resulting precipitate was then filtered, washed and dried at $382 \mathrm{~K}$. Samples of this material were then calcined (thermally treated) in a furnace open to air at various temperatures for 1 hour.

All samples were characterized, as described earlier [15], for their crystal phase and nanocrystallite size. Micro-Raman spectroscopy analysis was carried out employing an Invia-Microscope from Renishaw. For each sample spectra were recorded at room temperature (employing a $514 \mathrm{~nm}$ laser) at five to six different places and the results were averaged after having repeated the analysis several times.

The comparison of the different samples with regard to their photocatalytic activity was based on the degradation of methyl orange (MeO). $\mathrm{MeO}$ of analytical grade (Alfa Aesar, 99.99\%) was used as a simple model of a series of common azo-dyes that is largely used in industry in polymer fibre and plastics colourants. This material is known as an acid-base indicator, orange in basic medium and red in acidic medium. The structure of $\mathrm{MeO}$, represented in Figure 1, is characterized by sulphonic acid groups, which are known to be responsible for the high solubility of these dyes in water.

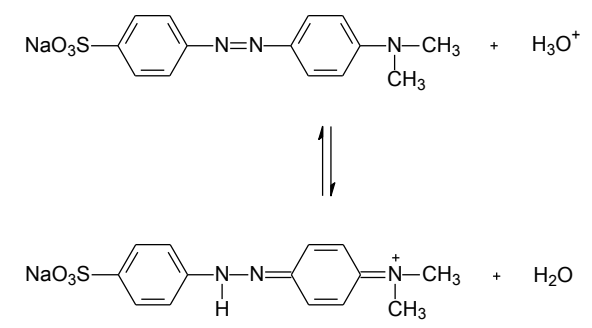


Figure 1. Structural formula of methyl orange (MeO).

When dissolved in de-ionized water, the UV-VIS spectrum of $\mathrm{MeO}$ exhibits two absorption maxima (Figure 3). The first band is observed at approximately $270 \mathrm{~nm}$ and the second, much more intense band, is observed at approximately $458 \mathrm{~nm}$. Changes in the height of these reference bands were used to monitor the degree of photocatalytic degradation of $\mathrm{MeO}$ by each of the nano-powder catalysts. Experiments were carried out at room temperature in a batch photo-reactor setup, consisting of a Pyrex volumetric flask open to air. The use of a magnetic stirrer ensured sufficient oxygenation from atmosphere as well as satisfactory mixing of the solution with the nano-powder catalyst. Irradiation of the mixture was accomplished by employing an artificial UV-visible light source emitting at a wavelength of $365 \mathrm{~nm}$ (the instrument used was a 'Rank Aldis Tutor 2'). The reaction mixture $(0.1 \mathrm{~L})$ was prepared by adding $0.3 \mathrm{~g}$ of $\mathrm{TiO}_{2}$ catalyst into de-ionized water containing $1 \mathrm{~mL}$ of $\mathrm{MeO}(0.06 \mathrm{M})$. The mixture was stirred and irradiated for 3 hours, while samples of $5 \mathrm{~mL}$ each were withdrawn from the reactor every 30 minutes and separated from the $\mathrm{TiO}_{2}$ particles employing a filtering syringe. The degree of photocatalytic degradation of $\mathrm{MeO}$ was monitored by measuring the absorbance value of the aqueous sample drawn at $458 \mathrm{~nm}$, employing a UV-visible spectrophotometer (Lambda $40 \mathrm{UV}$-VIS spectrometer) calibrated in accordance with the Beer-Lambert law [1-2].

\section{Results and discussion}

\subsection{Characterization}

For convenience the main Raman vibration modes for the three titania phases, i.e. anatase, brookite and rutile, are summarized in Table $1[29,32-34,36]$. The Raman spectra of the nano-powders calcined at different temperatures are presented in Figure 2. From Table 2 and Figure 3 it is evident that the brookite phase presence shows a downward/decreasing trend from $382 \mathrm{~K}$ up until $772 \mathrm{~K}$ and diminishes at 872 $\mathrm{K}$, whereas the anatase phase exhibits a directly related upward/increasing trend from $382 \mathrm{~K}$ to $772 \mathrm{~K}$ and dominates at $872 \mathrm{~K}$. A mixture of brookite and anatase is therefore observed up to $772 \mathrm{~K}$, with no rutile being present and the anatase phase being dominant over this temperature range. At $872 \mathrm{~K}$ all three phases of $\mathrm{TiO}_{2}$ are present and at $1097 \mathrm{~K}$ only rutile is present. The maximum brookite phase presence is therefore found at $382 \mathrm{~K}$ while the maximum anatase presence is reached at $872 \mathrm{~K}$. 
Table 1. Raman peak position $\left(\mathrm{cm}^{-1}\right)$ for bulk titanium dioxide phases [36-40].

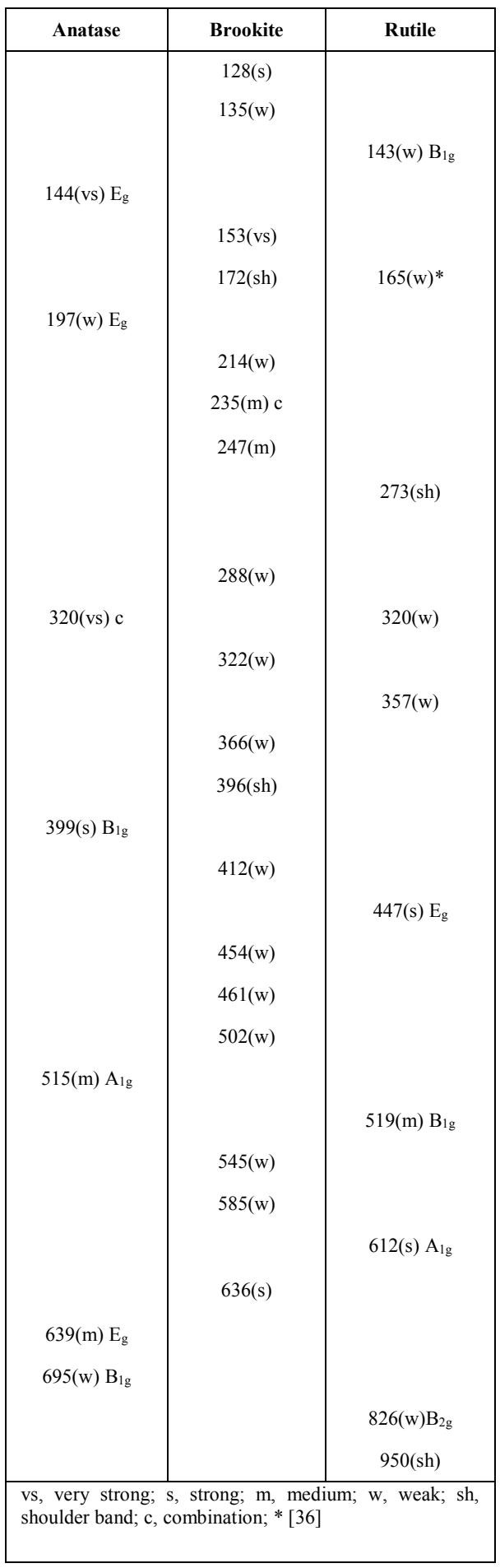




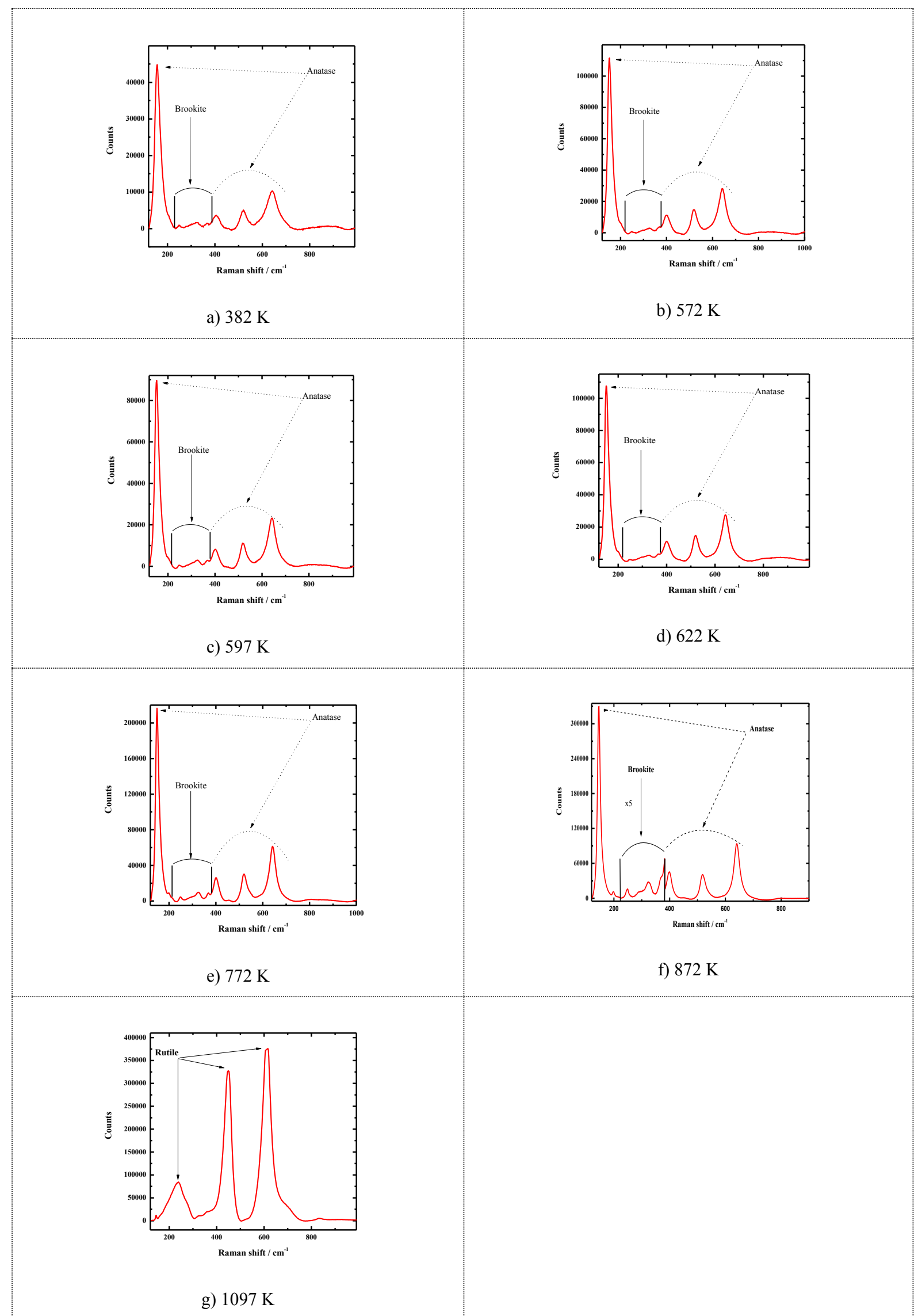

Figure 2. Raman spectra of the $\mathrm{TiO}_{2}$ nano-powders samples thermally treated at elevated temperatures (a) $382 \mathrm{~K}$, (b) $572 \mathrm{~K}$, (c) $597 \mathrm{~K}$, (d) $622 \mathrm{~K}$, (e) $772 \mathrm{~K}$, (f) $872 \mathrm{~K}$ and (g) $1097 \mathrm{~K}$. 
The crystallite size for both anatase and brookite increases slowly up to $972 \mathrm{~K}$ for anatase and $872 \mathrm{~K}$ for brookite, subsequent to which anatase and brookite disappear. Rutile makes its appearance at $872 \mathrm{~K}$ and a fairly dramatic increase in crystallite size is observed for rutile from $872 \mathrm{~K}$ to $1172 \mathrm{~K}$ (see Tables 2 and Figure 3). This observation, for the change in crystal structure with increased calcination temperature, is supported by the work of Kandiel et al. [35]. They observed the same trend for the calcination of 'anatase rich' $\mathrm{TiO}_{2}$ samples whereby anatase dominates brookite at low to intermediate temperatures and then converts to rutile at high temperatures. With regard to crystallite size the same general trend was observed in that anatase and brookite are comparable in size followed by a far greater rutile crystallite size [35].

Table 2. Effect of calcination temperature $(\mathrm{K})$ on phase composition and crystallite size (tw $=$ this work).

\begin{tabular}{|c|c|c|c|c|c|c|c|}
\hline \multirow{2}{*}{$\begin{array}{c}\text { Calcination } \\
\text { Temperature (K) }\end{array}$} & \multicolumn{3}{|c|}{ Crystalline Phase, \% } & \multicolumn{3}{|c|}{ Crystallite Size, nm } & \multirow[b]{2}{*}{ Ref. } \\
\hline & Anatase & Brookite & Rutile & Anatase & Brookite & Rutile & \\
\hline 382 & 60.3 & 39.7 & - & 5.3 & 3.4 & 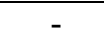 & $\mathrm{tw}$ \\
\hline 472 & 58.2 & 41.8 & - & 5.7 & 3.5 & - & 15 \\
\hline 572 & 65.6 & 34.4 & - & 6.6 & 5.4 & - & tw \\
\hline 597 & 63.0 & 37.0 & - & 7.0 & 4.4 & - & tw \\
\hline 622 & 62.2 & 37.8 & - & 7.2 & 5.7 & - & tw \\
\hline 672 & 68.7 & 31.3 & - & 8.3 & 6.2 & - & 15 \\
\hline 772 & 64.9 & 35.1 & - & 10.5 & 8.0 & - & tw \\
\hline 872 & 80.5 & 15.1 & 4.4 & 24.5 & 19.8 & 40.9 & tw \\
\hline 972 & 5.4 & - & 94.6 & 60.1 & - & 199.0 & 15 \\
\hline 1097 & - & - & 100.0 & - & - & 262.1 & tw \\
\hline 1172 & - & - & 100.0 & - & - & 498.8 & 15 \\
\hline
\end{tabular}
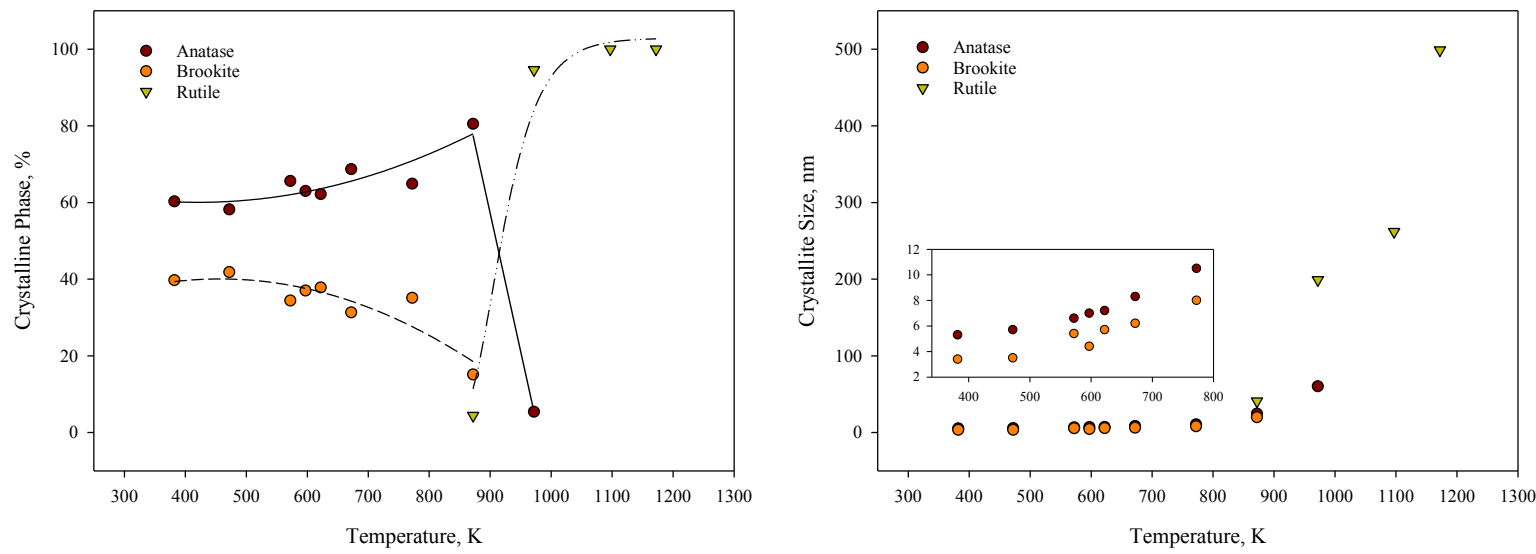

Figure 3. Effect of calcination temperature $(\mathrm{K})$ on phase composition and crystallite size. 


\subsection{Photocatalytic assessment}

The photocatalytic degradation of $\mathrm{MeO}$ exhibited a particularly high activity for the samples containing a mixture of anatase and brookite. An example of the optical absorption spectra showing the photocatalytic degradation of $\mathrm{MeO}$ with time is presented in Figure 3 for the photocatalyst calcined at $622 \mathrm{~K}$. The sample calcined at $382 \mathrm{~K}$ consisted of a mixture of approximately $60 \%$ anatase and $40 \%$ brookite and the sample thermally treated at $772 \mathrm{~K}$ is a mixture of approximately $65 \%$ anatase and $35 \%$ brookite (see Table.2).

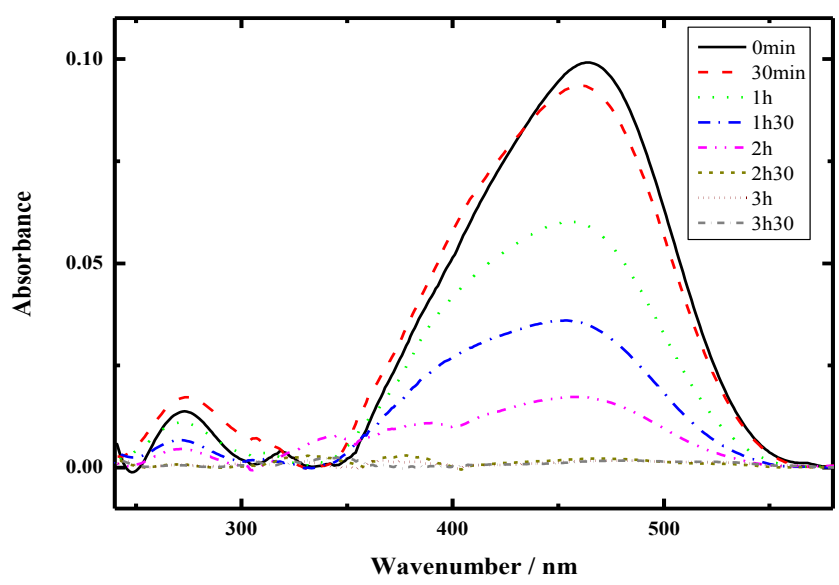

Figure 3. Optical absorption of $\mathrm{MeO}$ solution after light irradiation with the titania nano-powder sample calcined at $622 \mathrm{~K}$.

Figure 4 represents the normalized $\mathrm{MeO}$ concentration (\%) as a function of irradiation time, for all investigated samples. It is evident that all samples containing anatase-brookite mixtures exhibit high photocatalytic activity and it is furthermore clear that the sample calcined at $382 \mathrm{~K}$, which contained the highest percentage of brookite, also had the highest rate of $\mathrm{MeO}$ degradation, even if it is only fractionally so. Moreover, the sample calcined at $382 \mathrm{~K}$ almost totally degraded the $\mathrm{MeO}$ after 180 minutes of exposure time. The sample calcined at $872 \mathrm{~K}$, containing a mixture of anatase $(80.5 \%)$, brookite $(15.1 \%)$ and rutile $(4.4 \%)$, also exhibited a fairly high level of photocatalytic activity. It is therefore, evidently clear that all the samples investigated exhibited a fairly high degree of photocatalytic activity, except for the sample calcined at $1097 \mathrm{~K}$ that consisted of a pure rutile phase. It is furthermore evident that as the photocatalyst loses its anatase and brookite crystal phases, the photocatalytic activity diminishes dramatically. 


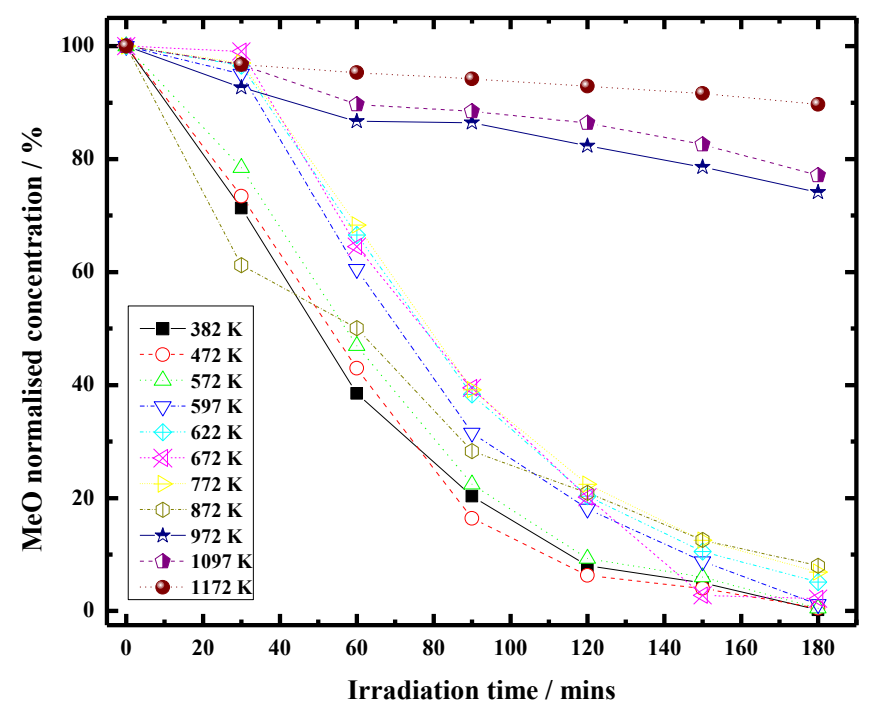

Figure 4. Normalized concentration (\%) of $\mathrm{MeO}$ monitored at $472 \mathrm{~nm}$ with time for suspensions of nanopowders calcined at different temperatures.

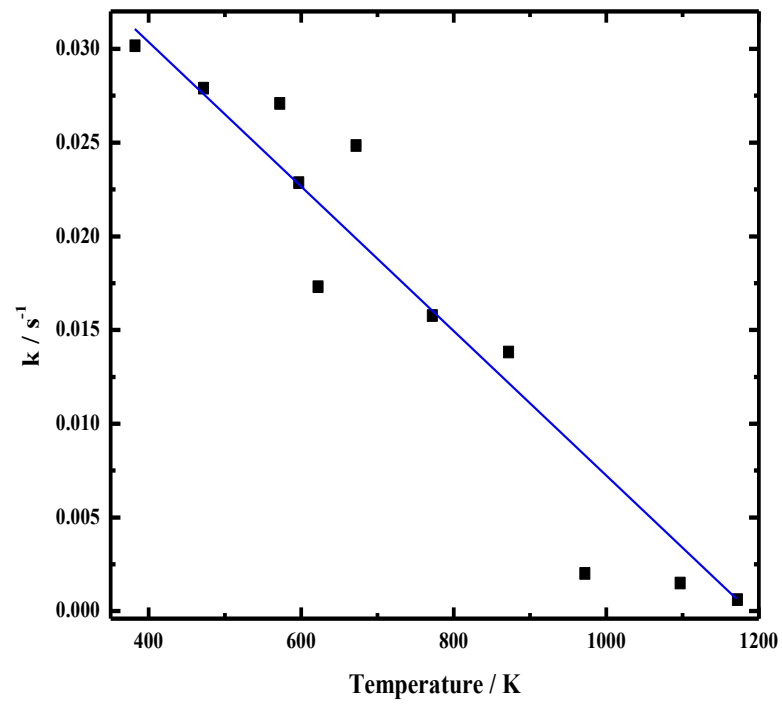

\begin{tabular}{|c|c|c|c|}
\hline $\mathbf{T}(\mathbf{K})$ & \multicolumn{3}{|c|}{ Anatase : Brookite : Rutile } \\
\hline 382 & 1.519 & 1 & 0 \\
\hline 472 & 1.392 & 1 & 0 \\
\hline 572 & 1.907 & 1 & 0 \\
\hline 597 & 1.703 & 1 & 0 \\
\hline 622 & 1.646 & 1 & 0 \\
\hline 672 & 2.195 & 1 & 0 \\
\hline 772 & 1.849 & 1 & 0 \\
\hline 872 & 5.331 & 1 & 0.291 \\
\hline 972 & 0.057 & 0 & 1 \\
\hline 1097 & 0 & 0 & 1 \\
\hline 1172 & 0 & 0 & 1 \\
\hline
\end{tabular}

Figure 5. The rate constant, $\mathrm{k}\left(\mathrm{s}^{-1}\right)$, for the photocatalytic degradation of Methylene Orange dye as a function of catalyst calcination temperature $(\mathrm{K})$ highlighting the Anatase: Brookite: Rutile ratio for each temperature.

As expected the crystallite sizes revealed thermally related grain growth of the particles. This is expected to have a negative effect on the photocatalytic activity as larger grain sizes lead to lower surface areas. The fact that fairly high photocatalytic activity is still evident for the sample that was 
calcined at $872 \mathrm{~K}$ can be understood on the basis of the improvement of carrier mobility (electron and hole mobility) subsequent to material calcination as well as the presence of brookite. Figure 5 represents the evolution of the reaction rate constant, $\mathrm{k}\left(\mathrm{s}^{-1}\right)$, for a first order reaction as a function of temperature $(\mathrm{K})$, and clearly shows how the rate of photocatalytic degradation reaction decreases as the temperature of thermal calcination increases.

The increase in crystallite size $(\mathrm{nm})$ as a function of the calcination temperature $(\mathrm{K})$ is evident from Figure 6 , and it is clear that the increasing crystallite size of both anatase and brookite (occurring concurrently from $382-872 \mathrm{~K}$ ) has a negative effect on the photocatalytic activity. Increasing crystallite size does however, go hand in hand with decreasing surface area (not monitored) and it could therefore, be argued that the decrease in the rate of reaction is as a result of decreasing surface area. However, it has been reported that pure anatase nano-particles, with a surface area three times that of pure brookite nano-particles, exhibited photocatalytic efficiency two times lower than that of brookite [35]. This observation was ascribed to the higher crystallinity of brookite. This is supported by the work of Štengl and Králová [30] who, investigating the photocatalytic degradation of Orange II dye, came to the conclusion that crystallinity is a more important factor than surface area for photocatalytic activity. In contrast, in a study investigating the photocatalytic activity of anatase titania as a function of crystallite size, for the decomposition of trichloroethylene, Jung et al. [41] have clearly shown an increase in photocatalytic activity with increasing crystallite size. The authors employed (i) spray pyrolysis using the precursor titanium ethoxide, and (ii) gas-phase pyrolysis using the precursor titanium tetraisopropoxide and found that the same trend was observed regardless of the synthesis method employed. The increase in activity with increased crystallite size is ascribed to an associated increase in the surface electron/hole density, which is as a result of the reduced recombination of electron/hole pairs due to longer migration distances in larger crystals. This leads to faster charge transfer between the excited electrons and holes on the crystals and their associated consumers. It has to be pointed out that, for the study conducted by Jung et al. [41], the anatase phase was dominant for all samples with rutile being less than $10 \%$ and with no brookite present. It would therefore seem that increasing crystalline size associated with a pure titanium phase (the work conducted by Jung et al. [41]) impacts photocatalytic activity positively, whereas increasing crystalline size associated with a mixed titanium phase (anatase and brookite, this work) impacts photocatalytic activity negatively.

Employing first principles, calculations (density functional theory) Park et al. [42] determined the band structures and density of states near the Fermi energy for anatase, rutile and brookite. The authors found band dispersion to decrease in the order rutile $>$ anatase $>$ brookite, with the density of states (within the window of $\pm 1.0 \mathrm{eV}$ of the Fermi energy) to be the greatest for brookite. This points towards the possibility of the photocatalytic efficiency for highly crystallized brookite to be greater than that of anatase. This is supported by the work conducted by Ismail et al. [43], on the photocatalytic evolution 
of hydrogen $\left(\mathrm{H}_{2}\right)$ from aqueous methanol solutions, who found that anatase/brookite mixtures and brookite nanorods exhibit higher photocatalytic activity than pure anatase nanoparticles. This was attributed to the fact that the conduction band of brookite is shifted more cathodically by $0.14 \mathrm{eV}$ relative to that of anatase.

When considering the percentage of crystal phase present in the titania sample as a function of the thermal calcination temperature $(\mathrm{K})$, it is clear that with increased thermal calcination temperature the anatase to brookite ratio increases (Figure 7). This increase in anatase to brookite ratio coincides with an increase of crystallite size (Figure 6) as well as with a decrease in the rate constant for the photocatalytic degradation of $\mathrm{MeO}$ (Figure 5). While it is generally accepted that photocatalytic activity goes hand in hand with the presence of the anatase crystal phase of titanium dioxide, the importance of the presence of the brookite phase, however, cannot but be emphasized. This is supported by Kandiel et al. [35] stating that a synergistic effect exists between anatase and brookite that enhances photocatalytic activity. One therefore, has to conclude that, with regard to the photocatalytic activity of the different samples, the phase presence of brookite plays a more important role than the crystalline size of anatase and brookite. The presence of brookite is therefore essential for photocatalytic activity that is greater than that of anatase alone. With the titania phase, crystallite size, surface area and band gap all impacting photocatalytic activity, one has to conclude that the observed photocatalytic activity cannot be attributed to a single property of the prepared photocatalysts. However, the presence of brookite would seem to be underestimated and a lot of gains are to be made by providing more focused attention to the inclusion of brookite as part of semiconductor photocatalysts.

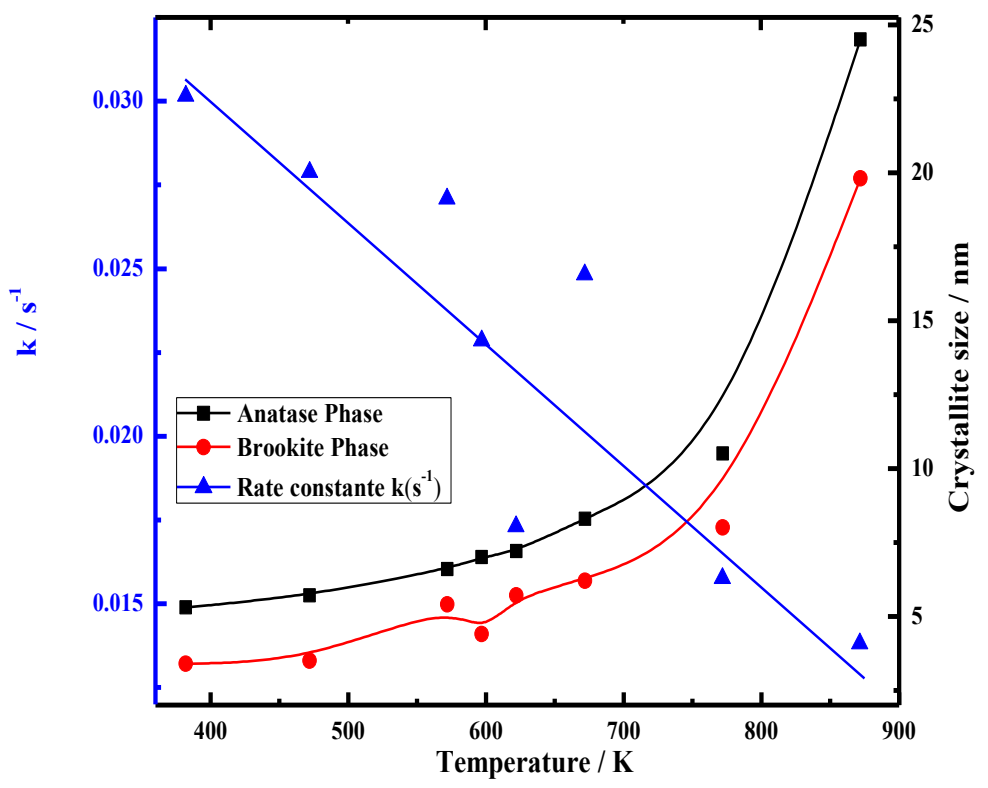

Figure 6. Evolution of the crystallite size (nm) as a function of calcination temperature (K). 


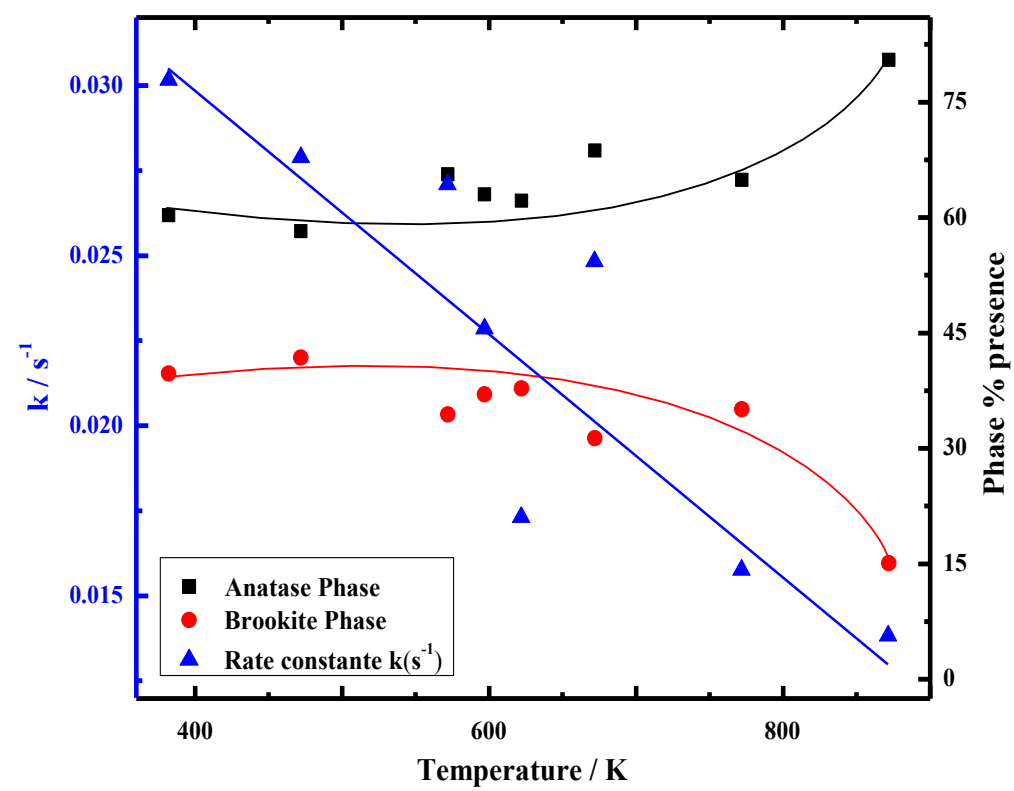

Figure 7. Evolution of the phase presence as a function of temperature (K).

\section{Conclusion}

Titanium dioxide samples containing significant amounts of brookite were prepared by hydrolyzing titanium tetraisopropoxide at room temperature and thermally calcining the product obtained from $382 \mathrm{~K}$ up to $1172 \mathrm{~K}$. Thermal calcination of the synthesized titanium dioxide resulted in different crystal phase ratios over this temperature range, with the anatase and brookite phases coexisting from $382 \mathrm{~K}$ to $872 \mathrm{~K}$, and a rutile only phase at the highest temperatures, i.e. $1097 \mathrm{~K}$ and $1172 \mathrm{~K}$. Assessment of the photocatalytic degradation of methyl orange under UV light, utilizing these photocatalytic materials, clearly exhibited the high activity of the mixed anatase and brookite phases for different anatase brookite ratios. Correlation between the reaction rate constant $\mathrm{k}\left(\mathrm{s}^{-1}\right)$, the crystallite size $(\mathrm{nm})$, the percentage of crystal phase present, and the temperature of thermal calcination $(\mathrm{K})$ revealed the dependence that high photocatalytic activity has on the presence of the brookite phase. The considerable loss of photocatalytic activity observed subsequent to $622 \mathrm{~K}$ coincided with a significant drop in the presence of the brookite phase and a simultaneous increase in the anatase phase, as well as an increase in crystallite size and therefore a reduction in surface area. Increased photocatalytic activity is therefore linked to an increase of the brookite phase, in the presence of anatase as the dominant phase, as well as a decrease of the crystallite size, i.e. increased surface area. Notwithstanding the fact that high photocatalytic activity has to be attributed to a conglomerate of properties of the prepared photocatalysts, the importance of the brookite phase in instilling high photocatalytic activity is clearly evident and should be afforded more focused attention. This behaviour has been explained by the fact that the conduction band edge of the brookite phase $\mathrm{TiO}_{2}$ is shifted more cathodically than that of anatase as was experimentally evidenced under dark and UV-vis illumination conditions [44]. This can have useful implications for the development of nanaoparticulate coatings in controlled degradation [45]. 


\section{References}

1. N. Guettaï, H. Ait Amar, Desalination, 185(1-3) (2005) 427-437.

2. $\quad$ Y. Badr, M.A. Mahmoud, J. Phys. Chem. Solids, 68(3) (2007) 413-419.

3. P.A. Christensen, T.A. Egerton, S.A.M. Kosa, J.R. Tinlin, Appl. Catal. B: Environ., 41 (2003) 371-386.

4. L. Di Paola, M. Bellardita, M. Cazzanelli, E. Palmisano, Thin Solid Films, 515(7-8) (2007) 3527-3529.

5. A. Fujishima, T.N. Rao, D.A. Tryk, J. Photochem. Photobiol. C, 1(1) (2000) 1-21.

6. N. Nakayama, T. Hayashi, Colloid. Surface. A, 317(1-3) (2008) 543-550.

7. A. Mills, S. Le Hunte, J. Photochem. Photobiol. A Chem., (1997) 1-35.

8. M.N. Chong, B. Jin, C.W.K. Chow, C. Saint, Water Res., (2010) 2997-3027.

9. M. Pelaez, N.T. Nolan, S.C. Pillai, M.K. Seery, P. Falaras, A.G. Kontos, P.S.M. Dunlop, J.W.J. Hamilton, J.A. Byrne, K. O’Shea, M.H. Entezari, D.D. Dionysiou, Appl. Catal. B: Environ., 125 (2012) 331-349.

10. B. Ohtani, J. Photochem. Photobiol. C, 11 (2010) 157-178.

11. L. Zhang, H.H. Mohamed, R. Dillert, D. Bahnemann, J. Photochem. Photobiol. C, 13 (2012) 263-276.

12. B. Guo, Z. Liu, L. Hong, H. Jiang, Surf. Coat. Tech., 198(1-3) (2005) 24-29.

13. Z. Liu, X. Zhang, T. Murakami, A. Fujishima, Sol. Energ. Mat. Sol. C., 92(11) (2008) 14341438 .

14. S. Boujday, P. Portes, J.F. Bocquet, C. Colbeau-Justin, Sol. Energ. Mat. Sol. C., 83 (2004) 421433.

15. N. Mahdjoub, N. Allen, P. Kelly, V. Vishnyakov, J. Photochem. Photobiol. A Chem., 210(2-3) (2010) 125-129.

16. M.P. Diebold, Surf. Coating. Int., 78(6) (1995) 250-256.

17. N. Martin, D. Rondot, F. Palmino, R. Mercier, Thin Solid films, 300 (1997) 113-121.

18. H.Z. Zhang, J.F. Banfield, J. Mater. Chem. 8 (1998) 2073-2076.

19. Y. Zhang, C.K. Chan, J.F. Porter, W. Guo, J. Mater. Res. 13 (1998) 2602-2609.

20. H.Z. Zhang, J.F. Banfield, J. Phys. Chem., B 104 (2000) 3481-3487.

21. R. Zallen, M.P. Moret, Solid State Commun., 137(3) (2006) 154-157.

22. M.Z. Moret, R. Vijay, D.P. Desu, B. Seshu, Thin Solid Films, 366(1-2) (2000) 8-10.

23. X. Bokhimi, F. Pedraza, J. Solid State Chem., 177(7) (2004) 2456-2463.

24. T. Ozawa, M. Iwasaki, H. Tada, T. Akita, K. Tanaka, S. Ito, J. Colloid Interf. Sci., 281(2) (2005) 510-513.

25. G.T. Luo, S.F. Wang, Z.C. Wang, Y. Ahuja, R. Johansson, B. Liu, J. Zou, Solid State Commun., 133(1) (2005) 49-53. 
26. A. Kuznetsova, V. Stambolova, I. Znaidi, L. Kanaev, Mater. Lett., 59(29-30) (2005) 38203823.

27. A. Di Paola, G. Cufalo, M. Addamo, M. Bellardita, R. Campostrini, M. Ischia, R. Ceccato, L. Palmisano, Colloid. Surface. A, 317(1-3) (2008) 366-376.

28. A. Di Paola, M. Addamo, M. Bellardita, E. Cazzanelli, L. Palmisano, Thin Solid Films, 515(78) (2007) 3527-3529.

29. B.I. Lee, X. Wang, R. Bhave, M. Hu, Mater. Lett., 60 (2006) 1179-1183.

30. V. Štengl, D. Králová, Mater. Chem. Phys., 129(3) (2011) 794-801.

31. R.C. Bhave, B.I. Lee, Mater. Sci. Eng. A, 467 (2007) 146-149

32. Y. Hu, H.L. Tsai, C.L. Huang, J. Eur. Ceram. Soc., 23(5) (2003) 691-696.

33. L. Jing, S. Li, S. Song, L. Xue, H. Fu, Sol. Energ. Mat. Sol. C., 92(9) (2008) 1030-1036.

34. D. Bersani, P.P. Lottici, T. Lopez, J. Non-Cryst. Solids, 232-234 (1998) 175-181.

35. T.A. Kandiel, L. Robben, A. Alkaim, D. Bahnemann, Photochem. Photobiol. Sci., 12 (2013) 602-609.

36. L.J. Alemany, M.A. Banares, E. Pardo, F. Martin-Jimenez, J.M. Blasco, Mater. Charact., 44(3) (2000) $271-275$.

37. J-G. Li, T. Ishigaki, Acta Mater., 52(17) (2004) 5143-5150.

38. I.M. Arabatzis, T. Stergiopoulos, M.C. Bernard, D. Labou, S.G. Neophytides, P. Falaras, Appl. Catal. B: Environ., 42(2) (2003) 187-201.

39. Y. Yu, J.C. Yu, J-G. Yu, Y-C. Kwok, Y-K. Che, J-C. Zhao, L. Ding, W-K. Ge, P-K. Wong, Appl. Catal. A: Gen., 289(2) (2005) 186-196.

40. N. Mahdjoub, N. Allen, P. Kelly, V. Vishnyakov, J. Photochem. Photobiol. A Chem., 211 (2010) 59-64.

41. K.Y. Jung, S.B. Park, S-K. Ihm, Appl. Catal. A: Gen., 224 (2002) 229-237.

42. J-Y. Park, C. Lee, K-W. Jung, D. Jung, Bull. Korean Chem. Soc., 30(2) (2009) 402-404.

43. A.A. Ismail, T.A. Kandiel, D.W. Bahnemann, J. Photochem. Photobiol. A Chem., 216 (2010) 183-193.

44. T.A. Kandiel, A. Feldoff, L. Robben, R. Dillert and D.W. Bahnemann, ACS, Chemistry of Materials, 22 (2010) 2050-2060.

45. M. Bestetti, D. Sacco, M.F. Brunella, S. Franz, R. Amadelli and L. Samiolo, Materials Chemistry and Physics, 124 (2010) 1225-1231. 